\title{
Quality Improvement of ABBS Hand Writing Batik Production through Standardization of Natural Dyeing using Water Guava and Mango Leaves
}

\author{
Nita Kusumawati* \\ Chemistry Departement \\ Universitas Negeri Surabaya \\ Surabaya, Indonesia \\ nitakusumawati@unesa.ac.id
}

\author{
Samik \\ Chemistry Departement \\ Universitas Negeri Surabaya \\ Surabaya, Indonesia \\ samik@unesa.ac.id
}

\author{
Anang Kistyanto \\ Economic Departement \\ Universitas Negeri Surabaya \\ Surabaya, Indonesia \\ anangkistyanto@unesa.ac.id
}

\begin{abstract}
Dyeing standardization in the production of ABBS SMEs natural dye hand writing batik has been done. A series of stages of pre-treatment, dyeing and fixation have been determined to obtain the desired shades, color intensity and fastness. Optimizing the quality of dyeing is done by washing mori fiber using Turkey Red Oil (TRO) and mordanting using alum and soda ash. The dyeing is done by pre-mordanting method using natural dyes from water guava and mango leaves. To avoid loss of color, especially in the "lorod"(dyes resistrelease)stage, fixation is applied using alum, lime and iron (II) sulfate. The overall standardization in the production of natural dye batik produced by ABBS SMEs resulted in the appearance of brown to black shades with a color intensity of 73.84\%-93.54\% and fastness on a scale of 2-4 on dyeing using water guava leaf extracts and the appearance of dark and light brown to bluish shades with a color intensity of 79.89\%-97.06\% and fastness on a scale of 3-4 on dyeing using mango leaf extract. Overall, mango leaf extract produces better dyeing quality on ABBS hand writing batik products.
\end{abstract}

\section{Keywords—Batik, SMEs, ABBS, natural dye}

\section{INTRODUCTION}

Batik is a form of the creation of valuable works of art, expressed in fabric motifs. Literally batik is a fabric that is specially made by applying a color barrier material (wax) to a fabric motif and then further processing it specifically. In line with the development of the social and cultural values of the Indonesian nation, batik grows and develops into a high-value national wealth and has received recognition from the United Nations through UNESCO as an intangible cultural heritage produced by Indonesia[1-3].

ABSS is a batik business that was established in 2013 in PaciranLamongan. As with the batik home industry in general, this batik business runs the production of hand writingbatik without standard operational procedures (SOP), so that the resulting product has unstable and homogeneous quality. Not only that, the ABBS batik business also still relies on synthetic dyes in its production. This condition causes the batik business to make a significant contribution to the deterioration in the quality of the surrounding environment, especially waters[47]. To overcome these problems, it is important to formulate a SOP on the ABBS hand writing batik production that utilizes biological resources in its dyeing.
Water Guava (Syzygiumaqueum) and mango (Mangiferaindica) are types of biological resources that are quite easy to find in every region in Indonesia [8]. A large abundance of the two commodities has produced by-products in the form of leaf waste. During this time, water and mango guava leaf waste has not been utilized at all. To prevent buildup, these two waste materials are generally burned. This is unfortunate because in addition to triggering air pollution, the tannin content allows both to be used as natural dyes in textiles. Tannins are phenolic compounds with high molecular weights (500-3,000 Da) that contain hydroxyl and other corresponding functional groups, such as carboxyl. Tannins are a class of polyphenolic compounds, which are generally soluble in polar solvents. This dye produces a brown color that tends to be dark and even black when reacting with metal ions, such as iron, calcium, copper and magnesium [9].

To get optimum color quality, the production of natural dyed batik must go through a sequence of stages, which includes pre-treatment, dyeing, fixation and barrier material removal. The successful implementation of pre-treatment, which includes washing and mordanting, is one of the determinants of the dyeing quality produced [10]. Washing with TRO will ensure that all parts of the fabric are free from contamination, while mordanting using alum and soda ash will provide an intermediate compound for reactions between hydroxide functional groups in the fabric fibers with functionally charged functional groups in the dye compound. Mordanting is one of the important stages in natural dyeing, considering that most natural dyes are dominated by negatively charged functional groups in their molecular structure [11-14].

Correspondingly, fixation also plays an equally important role in the production of natural dyed batik[15-16]. The successful implementation of fixation at the end of the dyeing procedure will largely determine the color fastness in batik. In principle, fixation is a color locking procedure, which will reduce the potential for color loss, especially during the "lorod" process (color barrierremoval). Besides affecting the quality, the fixer generally will also affect the color shades that emerge as a consequence of the content of the specific chromophore groups on the molecular structure.To get the dyeing procedure that produces optimum batik quality, this activity also evaluates the color quality produced from the dyeing method.The existence of SOP for natural dyeing will 
not only help the ABBS batik business, but also other batik businesses throughout Indonesia in order to obtain stable and homogeneous natural dyeing qualities.

\section{MATERIAL AND METHODS}

\section{A. Material}

Materials used in the production of ABBS batik include: (1) primisima mori fabric, which is obtained from Kak Wan Kain store (lamongan, Indonesia); (2) TRO ( $\geqslant 70 \%)$, obtained from CV. Dunia Kimia (Surabaya, Indonesia); (3) alum $\left(\mathrm{Al}_{2}(\mathrm{SO} 4)_{3} .18 \mathrm{H}_{2} \mathrm{O}\right.$, $\left.\geqslant 17 \%\right)$, obtained from PT. Brataco Chemistry (Surabaya, Indonesia); (4) soda ash $\left(\mathrm{Na}_{2} \mathrm{CO}_{3}, \geqslant\right.$ $48 \%$ ), obtained from CV. Water (Surabaya, Indonesia); (5) guava leaves and mango leaves, which are obtained from the environment around the ABBS batik business location (Lamongan, Indonesia); (6) fixers, which include: (a) iron (II) sulfate $\left(\mathrm{FeSO}_{4} .7 \mathrm{H}_{2} \mathrm{O}, \mathrm{d} 2.84 \mathrm{~g} / \mathrm{cm}^{3}\right)$, obtained from PT. Nusa Indah Megah (Surabaya, Indonesia); and (b) calcium oxide $(\mathrm{CaO}, \geqslant 90 \%)$, obtained from Mitra Water (Surabaya, Indonesia).Especially for alum fixers, the specifications of the material used are the same as those used for mordanting.

\section{B. Methods}

WashingTo free fabric fibers from polar and non-polar contaminants, ABBS SMEs conduct washing using TRO. Washing solutions are prepared by dissolving 0,086 g TRO in $1 \mathrm{~L}$ of water. While washing is done by soaking $275 \mathrm{~g}$ fabric $(2 \mathrm{~m} \times 1.5 \mathrm{~m})$ in TRO solution for $6 \mathrm{~h}$. As soon as washing is done, rinsing is done 3 times, each using $7,8 \mathrm{~mol}$ of water. Fabric that has been through the rinsing stages, dried in the open air for $24 \mathrm{~h}$.

Mordant.To improve the ability of fabric fibers that are able to react with natural dyes from water guava and mango leaves as well as a combination of both, ABBS SMEs conduct mordanting using alum and soda ash. Mordant solutions are prepared by dissolving $660 \mathrm{~g}$ alum and $165 \mathrm{~g}$ soda ash in 7.8 $\mathrm{L}$ water. So that the dissolution works perfectly, stirring using an agitator for $5 \mathrm{~min}$. The mordant solution is then heated to boiling. Immediately after boiling, put in a $275 \mathrm{~g}$ fabric and allowed to stand while continuing to heat for $1 \mathrm{~h}$. After that, the heating is stopped, but the fabric is left to soak in a mordant solution for $24 \mathrm{~h}$. As soon as the mordanting is finished, it is rinsed 3 times, each using $7800 \mathrm{~mL}$ water and then drying in the open air for $24 \mathrm{~h}$. Primisima Mori fabric that has been dried, ironed to get a uniform fiber orientation.

Dyeing. To get the best quality dyeing, ABSS SMEs do the dyeing by the pre-mordanting method. Dyes extracts from water guava and mango leaves were prepared by dissolving material that had been blended into a water solvent, with a material/solvent ratio of 1:10. To optimize the dissolution of tannin dyes compounds from the two raw materials, continuous heating is carried out until the extract volume is half the initial volume. After this process, the dye extract is ready to be used in dyeing.

Dyeing is done through a procedure soaking $275 \mathrm{~g}$ fabric in $825 \mathrm{~mL}$ extract water guava and mango leaves for $5 \mathrm{~min}$ and then drained. The same procedure was repeated up to 8 times, to optimize the reaction between the dye and the mordant that had been bound to the fabric fiber. Immediately after 8 times dyeing, the fabric is fixed using all three types of fixers.
In line with mordanting, fixation is done to obtain high color fastness. The three fixer solutions, namely iron (II) sulfate, alum and lime, were prepared using the same method, by dissolving $50 \mathrm{~g}$ fixers in $1 \mathrm{~L}$ of water. To optimize the solubility of each fixer compound in a water solvent, stirring was carried out using an agitator for $5 \mathrm{~min}$. The solution is then allowed to stand for $24 \mathrm{~h}$, to get the clear part. This part is used for fixation or locking the color on fabric. Next, fixation was done by soaking $275 \mathrm{~g}$ of fabric in $825 \mathrm{~mL}$ fixer solution for $10 \mathrm{~min}$. For the final, the fabric is dried in the open air for $24 \mathrm{~h}$.

Characterization. To find out the color quality of hand writing batik produced by ABBS SMEs after standardization, a number of analyzes were conducted, including: (1) color intensity analysis using Shimadzu UV-2401-PC Diffuse Reflectant Ultraviolet (DRUV) Spectrophotometer. In this analysis, high reflectance values indicate low color intensity; and (2) color fastness analysis using the Gray Staining Scale method. Interpretations of the results of this analysis can be seen in Table 1.

TABLE I. INTERPRETATION OF COLOR FASTNESS USING THE GRAY STAINING SCALE METHOD

\begin{tabular}{ccc}
\hline No & Value & $\begin{array}{c}\text { Color Fastness } \\
\text { Interpretation }\end{array}$ \\
\hline 1 & 1 & Bad \\
\hline 2 & $1-2$ & Bad \\
\hline 3 & 2 & Not good enough \\
\hline 4 & $2-3$ & Not good enough \\
\hline 5 & 3 & Fair \\
\hline 6 & $3-4$ & Good enough \\
\hline 7 & 4 & Good \\
\hline 8 & $4-5$ & Very good \\
\hline 9 & 5 &
\end{tabular}

\section{RESULT AND DISCUSSIONS}

Utilization of TRO in mori raw material washing by ABBS SMEs is to ensure the solubility of a number of contaminants deposited on the fabric fibers. The semi-polar nature of TRO allows TRO to dissolve water and fat based contaminants. Thus, fabric raw materials can more easily accept mordant entry. The more free the fabric is from contaminants, the more optimal the mordant that can be bound to the fabric fibers, to further bridge the reaction with the dye. In Fig. 1 we can see the process of raw materials washing by the ABBS SMEs.

As explained earlier, the presence of alum mordants with positively charged aluminum metal ions with a valence of three, will allow the reaction between negatively charged hydroxide groups which dominate the mori fibers and functional groups of anionic dyes. The optimal number of mordants that can react with fabric fibers, the higher the color quality produced. In Fig. 2, a mordanting procedure for primisima mori fabric is performed by ABBS SMEs. 


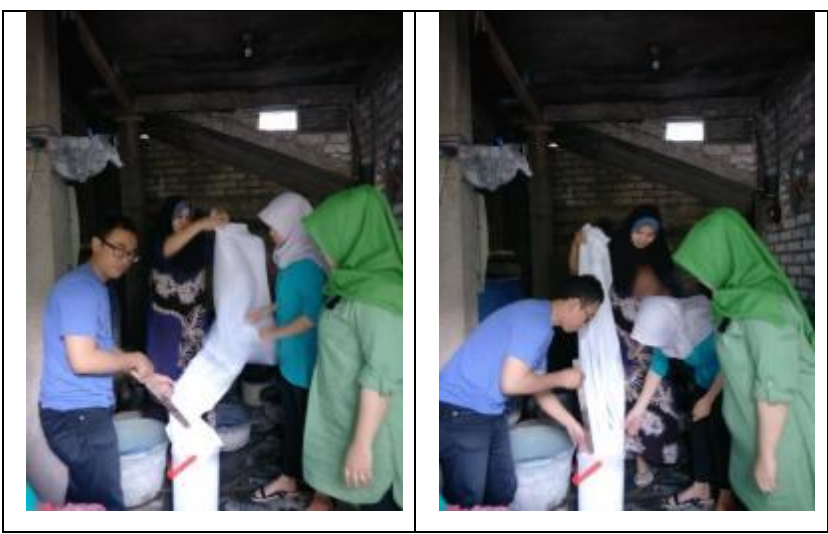

Fig. 1. The fabric washing stages using TRO conducted by ABBS SMEs

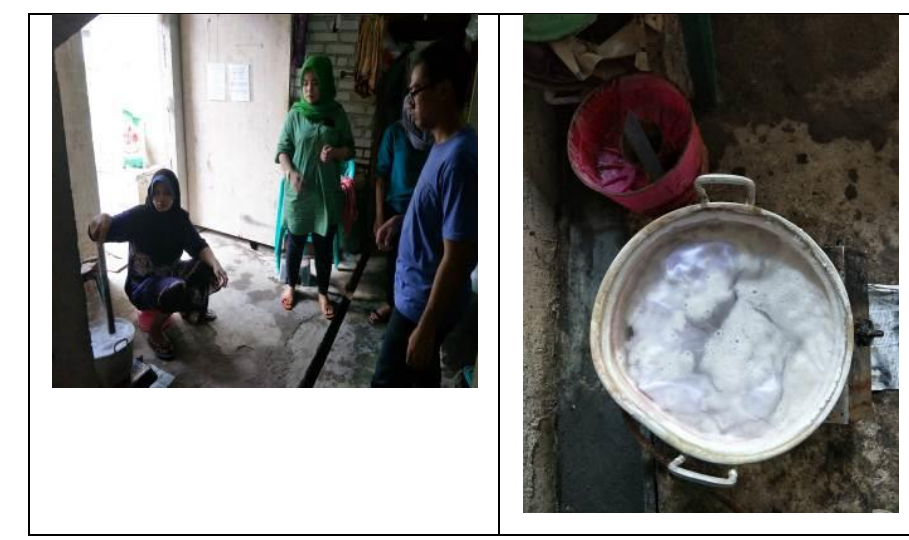

Fig. 2. The fabric mordanting stages conducted by ABBS SMEs

The raw material of the fabric that has gone through the mordanting stages, is then ready to be dyed using water guava and mango leaf extracts. Fig. 3 shows the extract color shades of it's material, while Fig. 4 shows the dyeing procedure carried out by ABBS SMEs. To get the dyeing and fixation methods that are able to produce the best color quality on ABBS batik products, it is evaluated the differences in shade, intensity and color fastness produced by the spesificdyeing methods.

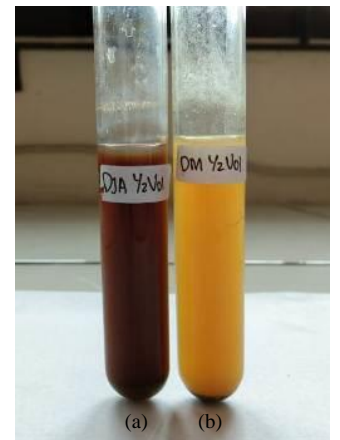

Fig. 3. The color shades of the : (a) water guava; and (b) mango extract used in the ABBS SMEs dyeing process

Fixation is the final stage of dyeing which aims to lock the color of the fiber so it is not easily degraded by sunlight and ironing heat and washed out in the washing process. The presence of fixer compounds that seem to be color coatings will reduce the reactivity of dye compounds to the components of the surrounding environment. Thus, the color fastness can be maintained or even improved. Table 1 presents colors shades resulting from the application of various dyes and fixers.

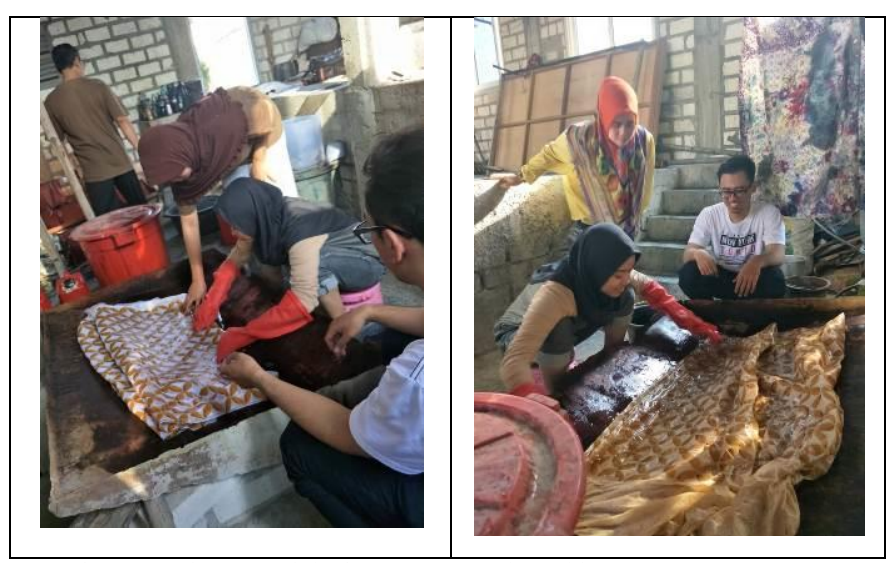

Figure 4. The natural dyeing stages conducted by ABBS SMEs

TABLE II. COLOR SHADES OF PRIMISIMA MORI FIBER PRODUCED FROM NATURAL DYEING USING WATER GUAVA AND MANGO LEASVES

\begin{tabular}{lll}
\hline No & $\begin{array}{c}\text { Dyes-Fixer } \\
\text { Combination }\end{array}$ & Result of dyes \\
\hline
\end{tabular}

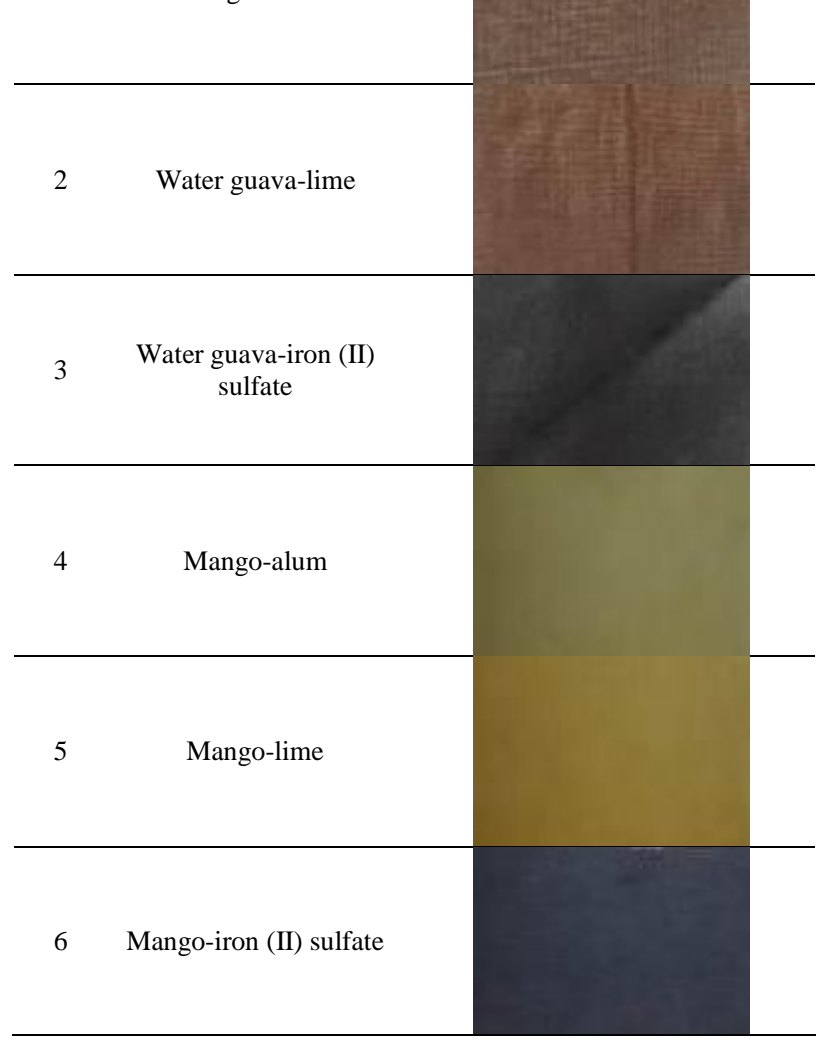

$1 \quad$ Water guava-alum 
The results of the dyeing show the appearance of brown shades on mori fibers that are dyed using water guava leaf extracts, while dyeing using mango leaf extracts produces more varied shades as the three different fixers are applied, where alum fixation produces dark brown, alum produces a light brown, while iron (II) sulfate produces a bluish color. Table 2 shows the color intensity produced by each combination of dyes and fixers.

TABLE III.

THE COLOR INTENSITY WITH A DIFFERENT COMPOSITIONS AND FIXER

\begin{tabular}{llll}
\hline \multirow{2}{*}{ No } & $\begin{array}{l}\text { Dyes-Fixer } \\
\text { Combination }\end{array}$ & Color & \\
\cline { 2 - 4 } & Water guava-alum & 73.84 & Fastness (1-5) \\
\hline 1 & Water guava-lime & 86.23 & $2-4$ \\
\hline 3 & $\begin{array}{c}\text { Water guava-iron (II) } \\
\text { sulfate }\end{array}$ & 93.54 & $3-4$ \\
\hline 4 & Mango-alum & 79.89 & 4 \\
\hline 5 & Mango-lime & 97.06 & $3-4$ \\
\hline 6 & $\begin{array}{c}\text { Mango-iron (II) } \\
\text { sulfate }\end{array}$ & 88.96 & 3 \\
\hline
\end{tabular}

The results of the color intensity analysis show that overall, mango leaf extract is able to produce shades with higher intensity and fastness. This is predicted to be closely related to differences in the content of tannin compounds in both extracts and the significance of interference triggered by the presence of other dyeing compounds as competitors in reacting with mordanting agents. More specifically, dyeing with the highest intensity and fastness in dyeing using guava leaf extract is produced by fixer iron (II) sulfate, while alum fixer shows its dominance in dyeing using mango leaf extract.

\section{CONCLUSIONS}

Efforts to standardize dyeing in the production of ABBS batik have been carried out, through the application of washing with TRO, mordanting with alum and soda ash, dyeing with the pre-mordanting method, and fixation using iron(II) sulfate, alum and lime. The overall standardization in the production of natural dye batik produced by ABBS SMEs resulted in the appearance of brown to black shades with a color intensity of $73.84 \%-93.54 \%$ and fastness on a scale of 2-4 on dyeing using water guava leaf extracts and the appearance of dark and light brown to bluish shades with a color intensity of $79.89 \%-97.06 \%$ and fastness on a scale of 3-4 on dyeing using mango leaf extract. Overall, mango leaf extract produces better dyeing quality on ABBS hand writing batik products.

\section{ACKNOWLEDGMENT}

Thank you to the Ministry of Research and TechnologyHigher Education of Indonesia Republic for the financial support provided through the Community Partnership Program activities.

\section{REFERENCES}

[1] A. Wulandari. "Batik nusantara: Makna filosofis, cara pembuatan, dan industri batik." ANDI: Yogyakarta, 2011.

[2] Kusumawati, N., Muslim, S., Kistyanto, A. 2016. Operational conditions optimization on blacu fabric dyeing technology (case study: mordanting influence on naphtol color quality and mechanical strength of blacu fiber. Research Journal of Pharmaceautical Biological and Chemical Sciences 7(5): pp. 33-42.

[3] Kusumawati, N., Koestiari, T., Santoso, A.B. 2015. The influence of washing process using TRO on indigosol dyeing quality, leaching percentage, and mechanical strength of mori fabric. Research Journal of Pharmaceautical Biological and Chemical Sciences 6(6): pp. 55-63.

[4] T. Rossi, P.M.S Silva, L.F. De Moura, M.C. Araujo, J.O. Brito, H.S. Freeman, "Waste from eucalyptus wood steaming as a natural dye source for textile fibers". Journal of Cleaner Production, vol. 143, pp. 303, 2017.

[5] M.A.R. Bhuiyan, A. Islam, A. Ali, M.N. Islam, "Color and chemical constitution of natural dye henna (Lawsoniainermis L) and its application in the coloration of textiles". Journal of Cleaner Production, vol. 167, pp. 14-22, 2017.

[6] M. Yusuf, Shahid-ul-Islam, M.A. Khan, F. Mohammad, "Investigations of the colourimetric and fastness properties of wool dyed with colorants extracted from Indian madder using reflectance spectroscopy". Optik, vol 127, pp. 6087-6093, 2016.

[7] K.M. Zia, S. Adell, Fazal-ur-Rehman, H. Aslam, M. K. Khosa, M. Zuber, "Influence of ultrasonic radiation on extraction and green dyeing of mordanted cotton using neem bark extract". Journal of Industrial and Engineering Chemistry, vol. 77, pp. 317-322, 2019.

[8] S.A. Danarto, S. Budiharta, Fauziah, "Tree species preference and rehabilitation perspective by local community: Case study in Bondowoso, East Java, Indonesia". Asian Journal of Forestry, vol. 3(2), pp. 54-63, 2019.

[9] N. Kusumawati, L. Mufida, R.A. Annisa, "Pewarna alami untuk tekstil.” Surabaya: Unesa University Press, 2018.

[10] A. Frose, K. Schmidtke, T. Sukmann, I.J. Junger, A. Ehrmann, "Application of natural dyes ondiverse textile materials". Optik, vol. 181, pp. 215-219, 2018.

[11] S. Adeel, Fazal-ur-Rehman, M.U. Iqbal, N. Habib, S. Kiran, M. Zuber, K.M. Zia, A. Hameed, "Ultrasonic assisted sustainable dyeing of mordanted silk fabric using arjun (Terminalia arjuna) bark extracts". Environmental Progress \&amp; Sustainable Energy, vol 38(S1), 2019.

[12] S. Islam, I.J. Rather, M. Shabbir, J. Sheikh, M.N. Bukhari, M.A. Khan, F. Mohammad, "Exploiting the potential of polyphenolic biomordants in environmentally friendly coloration of wool with natural dye from butea monosperma flower extract".J. Nat. Fibers, vol. 1, pp. 1-2, 2018.

[13] Kusumawati, N. Santoso, A.G., Sianita, M.M., Muslim, S. 2017.Extraction, characterization, and application of natural dyes from the fresh mangosteen (Garcinia mangostana L.) peel. International Journal on Advanced Science, Engineering, Information Technology, 7(3): pp. 878-884.

[14] Kusumawati, N., Samik, Santoso, A.B., Wijiastuti, A. 2018. Development of textile natural dyeing using hybrid dyes from mango leaves turmeric.Advances in Engineering Research, 171: pp. 50-55.

[15] B. Patel, P. Kanade, "Sustainable dyeing and printing with natural colours vis-à-vis preparation of hygienic viscose rayon fabric". Sustainable Materials and Technologies, vol. 22, pp. 1-9, 2019.

[16] L. Liu, B. Mu, W. Li, Y. Yang, "Cost-effective reactive dyeing using spent cooking oil for minimal discharge of dyesand salts". Journal of Cleaner Production, vol. 227, pp. 1023-1034, 2019. 